Gut, 1976, 17, 900-905

\title{
Depressed cell-mediated immunity in coeliac disease
}

\author{
B. B. SCOTT AND M. S. LOSOWSKY
}

From the University Department of Medicine, St. James's Hospital, Leeds

SUMMARY Fourteen coeliac patients on a gluten free diet (GFD) and 10 on a normal diet were studied by lymphocyte transformation in response to PHA to assess the integrity of cell-mediated immunity (CMI). Transformation was depressed in the majority taking a normal diet, with improvement after a GFD. In some patients the depression may have been due to a serum factor, as transformation was more nearly normal when the lymphocytes were cultured in pooled AB serum than in their own serum. There was no correlation between transformation and nutritional deficiencies. Mantoux tests were performed in some of these and other coeliac patients and there was a very significant reduction in the incidence of positive tests compared with controls. These findings provide evidence of depressed CMI in coeliac patients taking a normal diet with improvement on a GFD and may be of relevance to the high risk of malignancy in coeliac disease, further strengthening the case for a strict GFD.

One of the most serious complications of coeliac disease is malignancy, particularly lymphoma, both of the small bowel and elsewhere, affecting perhaps $10 \%$ of patients after a mean interval after diagnosis of nine to 20 years (Austad et al., 1967; Harris et al., 1967; Gough et al., 1972; Stokes et al., 1974). The available evidence suggests that the risk is reduced in those taking a gluten-free diet (GFD).

Why malignancy in general and small-bowel malignancy in particular should be so common in coeliac disease, is not known. Small bowel malignancy could be a result of the local, longstanding inflammation, the increased mitotic activity of epithelial or lymphoid cells, or a disturbance in local immune protection in an organ which is uncommonly affected by malignancy (Lowenfels, 1973). Malignancy could also be caused by dietary carcinogens absorbed through the damaged mucosa (Wattenberg, 1966; Cooke, 1970) or lack of immunosurveillance (Burnet, 1967), due perhaps to depressed immunity.

Depressed immunity in coeliac disease is suggested by lymphoreticular atrophy (McCarthy et al., 1966) and subnormal responses to immunisation (Beale $e t$ al., 1971; Baker et al., 1974). In vivo skin tests of cellmediated immunity (CMI) have not been reported (except to gluten) but several groups (Winter et al., 1967; Blecher et al., 1969; Housley et al., 1969; Ansaldi et al., 1970; Popovíc et al., 1970; Maclaurin et al., 1971; Morganroth et al., 1972), have studied lymphocyte transformation in response to PHA which

Received for publication 29 June 1976 is the usual in vitro test of CMI. It can be seen (Table 1) that the results are inconclusive. In the light of detailed published studies of lymphocyte responses to PHA, it seems that methods used in these reports may not have been sufficiently discriminating. Morphological or autoradiographical assessment was used in five of the reports, and these techniques are subjective and less accurate than scintillation counting (Schellekens and Eijsvoogel, 1968; Hughes and Caspary, 1970). In none was more than one concentration of PHA used: the importance of using a range of concentrations to obtain a dose-response curve has been stressed (Richter and Naspitz, 1967; Hughes and Caspary, 1970; Fitzgerald, 1971, 1972). The studies employing scintillation counting used only two and three replicates, but the known variation between replicates suggests that even five replicates may be barely sufficient for highestaccuracy (Caspary and Hughes, 1972).

This study investigates the integrity of CMI in coeliac disease, in relation to nutritional deficiencies and treatment with a GFD, using both Mantoux testing and a lymphocyte transformation technique incorporating recommended modifications.

\section{Methods}

\section{PATIENTS AND CONTROLS}

Lymphocyte transformation

A control range was obtained from results in 13 healthy volunteers, mainly hospital personnel. The mean age was 30 years and 10 were male. The coeliac 
Table 1 Reported studies of PHA-induced lymphocyte transformation in patients with coeliac disease

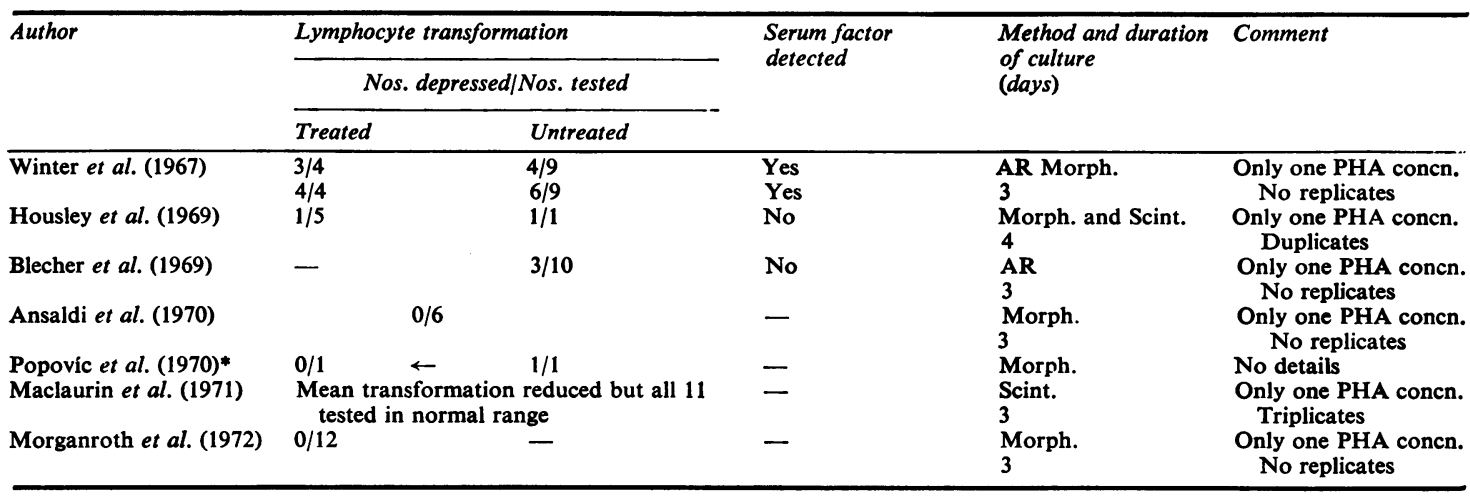

AR: autoradiography. Morph: morphological. Scint.: scintillation counting.

*The single patient reported had depressed transformation which became normal after treatment.

patients consisted of 10 on a normal diet (mean age 26 years; four males) and 14 on a GFD (mean age 40 years; six males). Six patients were in both categories having been studied before and after treatment. The diagnosis of coeliac disease was based on an unequivocal histological response of the jejunal mucosa to a GFD (Booth, 1970) in all except eight of the patients; these had flat jejunal biopsies and no other apparent cause, but a histological response had not yet been demonstrated.

\section{Mantoux tests}

Details of the patients and controls are shown in Table 2. Eleven of the controls were healthy volunteers and single patients had one of the following diagnoses: obstructive jaundice, perforated colon, alcoholic cirrhosis, Crohn's disease, cystic fibrosis, pancreatitis, retinopathy, poor diet, and small stature.

\section{TECHNIQUES}

\section{Lymphocyte transformation}

A whole-blood technique based on that described by Paty and Hughes (1972) was used. Each culture consisted of $0.1 \mathrm{ml}$ heparinised blood, $0.6 \mathrm{ml}$ serum, and $2.3 \mathrm{ml}$ medium TC199 (Wellcome), with or without PHA, in $15 \mathrm{ml}$ siliconised, glass, conical centrifuge tubes. Parallel cultures were made up with pooled AB serum obtained, free of lymphocytotoxic activity, from the Regional Blood Transfusion Laboratory and autologous serum obtained by defibrination of the patient's blood. Six concentrations of reconstituted PHA (bactophytohemagglutinin P, Difco Labs, Detroit, USA) were used such that its final concentrations in the cultures were $0,0.7 \times 10^{-4}, 2.2 \times$ $10^{-4}, 4.8 \times 10^{-4}, 7.6 \times 10^{-4}, 9.6 \times 10^{-4} \mathrm{ml} / \mathrm{ml}$ culture. Four replicates were used, more were impractical in view of the number of concentrations and the parallel studies using two sources of serum. A control subject was usually studied at the same time as each patient.

The cultures were left at $37^{\circ} \mathrm{C}$ for 72 hours. Four hours before the end of this culture period, $0.05 \mathrm{ml}$ tritiated thymidine (specific activity 5.0 curies $/ \mathrm{mmol}$; Radiochemical Centre, Amersham, UK) was added to give a concentration in the culture mixture of 0.8 $\mu \mathrm{Ci} / \mathrm{ml}$. At the end of culture, transformation was assessed by the DNA-incorporated thymidine measured by liquid scintillation counting of the TCAprecipitable material dissolved in hyamine hydroxide. The mean result of the four replicates was expressed as counts per minute (CPM)/10 $10^{6} \mathrm{lym}$ phocytes.

This particular technique was validated as a test of CMI by correlating the response of the lymphocytes in vitro to tuberculin with the result of Mantoux testing 20 positive and negative subjects. The correlation was absolute except in one subject who was suffering from a respiratory infection at the time of lymphocyte testing.

\section{Lymphocytotoxic antibodies}

Cytotoxic antibodies were sought in the serum of patients by the method of Terasaki and McClelland

Table 2 Results of Mantoux tests in patients and controls

\begin{tabular}{|c|c|c|c|c|c|c|c|}
\hline \multirow[t]{2}{*}{ Diagnosis } & \multirow{2}{*}{$\begin{array}{l}\text { Mean } \\
\text { age } \\
\text { (yr) }\end{array}$} & \multicolumn{3}{|c|}{ Numbers } & \multicolumn{2}{|c|}{$\begin{array}{l}\text { Mantou } \\
\text { positive }\end{array}$} & \multirow[t]{2}{*}{$\boldsymbol{P}$} \\
\hline & & Male & Female & Total & (no.) & $(\%)$ & \\
\hline $\begin{array}{l}\text { Coeliac-GFD } \\
\text { Coeliac-ND } \\
\text { Coeliac-All } \\
\text { Controls }\end{array}$ & $\begin{array}{l}48 \\
37 \\
44 \\
39\end{array}$ & $\begin{array}{r}6 \\
2 \\
8 \\
10\end{array}$ & $\begin{array}{r}5 \\
5 \\
10 \\
10\end{array}$ & $\begin{array}{r}11 \\
7 \\
18 \\
20\end{array}$ & $\begin{array}{r}3 \\
1 \\
4 \\
17\end{array}$ & $\left.\begin{array}{l}27 \\
14 \\
22 \\
85\end{array}\right\}$ & $\begin{array}{c}\text { NS } \\
<0.001\end{array}$ \\
\hline
\end{tabular}


(1964) using a panel of lymphocytes of 24 different HL-A specificities.

\section{Nutritional assessment}

Blood taken at the same time as for the lymphocyte transformation studies was used for a detailed nutritional assessment consisting of the following measurements: haemoglobin; serum iron, folate, $B_{12}$, vitamin $\mathrm{A}$, vitamin $\mathrm{E}$, carotene, albumin and calcium; red cell folate; and leucocyte vitamin $\mathrm{C}$.

\section{Mantoux tests}

These were performed using $1: 1000$ or $1: 10,000$ PPD tuberculin (Weybridge) injected intradermally at the anterior aspect of the forearm and inspected for induration between 48 and 72 hours afterwards. Positive tests were recorded if the diameter of induration exceeded $10 \mathrm{~mm}$. If a test was negative using 1:10,000 tuberculin, it was repeated with $1: 1000$ tuberculin.

\section{Statistical analysis}

The Mann-Whitney U test was used to determine the significance of the difference between lymphocyte responses in coeliac patients and controls. Fisher's exact test was used to determine the significance of the difference in frequency of subnormal lymphocyte

responses-that is, below the observed control range.

\section{Results}

\section{LYMPHOCYTE TRANSFORMATION}

The dose-response curves of PHA induced lymphocyte transformation are shown in Figs. 1-3. The untreated coeliac patients had significantly reduced transformation compared with controls in both autologous and pooled AB serum $(P<0.02)$. The treated patients had significantly reduced transformation in autologous serum $(P<0.05)$ but not in pooled AB serum $(P>0 \cdot 1)$. The responses in treated patients were significantly higher than in untreated patients in pooled $A B$ serum $(P=0.03)$, but not in autologous serum $(P=0.06)$. Responses in pooled $A B$ serum were significantly higher than in autologous serum in patients on a GFD $(P=0.04)$ but not in those taking a normal diet $(P=0 \cdot 16)$.

The improvement in response after treatment is better demonstrated in Fig. 3 in which the results of six patients studied both on a normal diet and a GFD are presented. In both pooled AB serum and autologous serum, responses improved, usually to normal, in all except two patients-one who already had normal transformation and one who had been on a GFD for only three months.

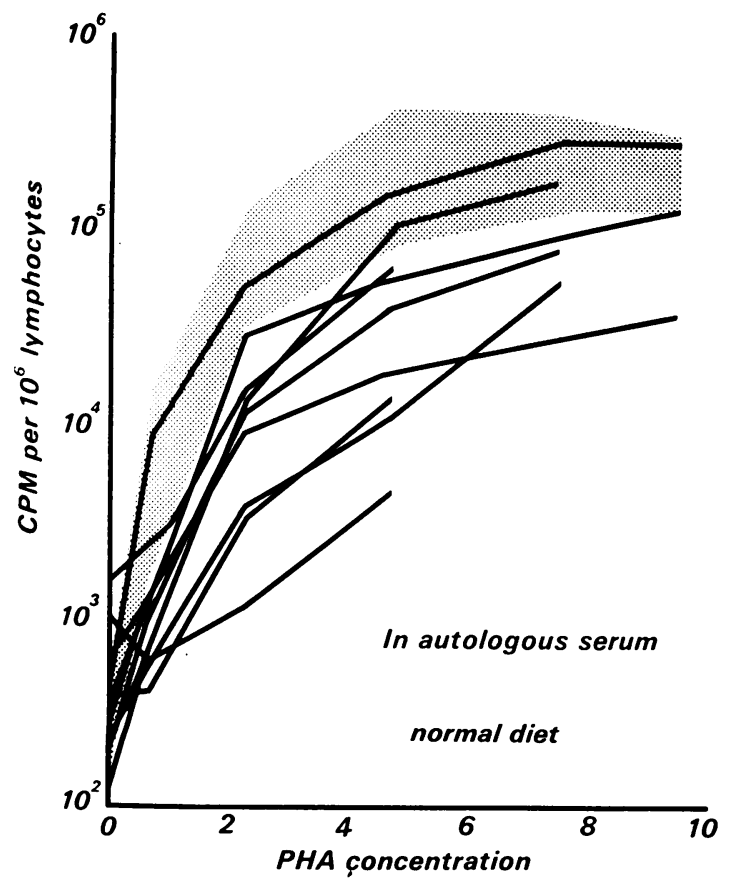

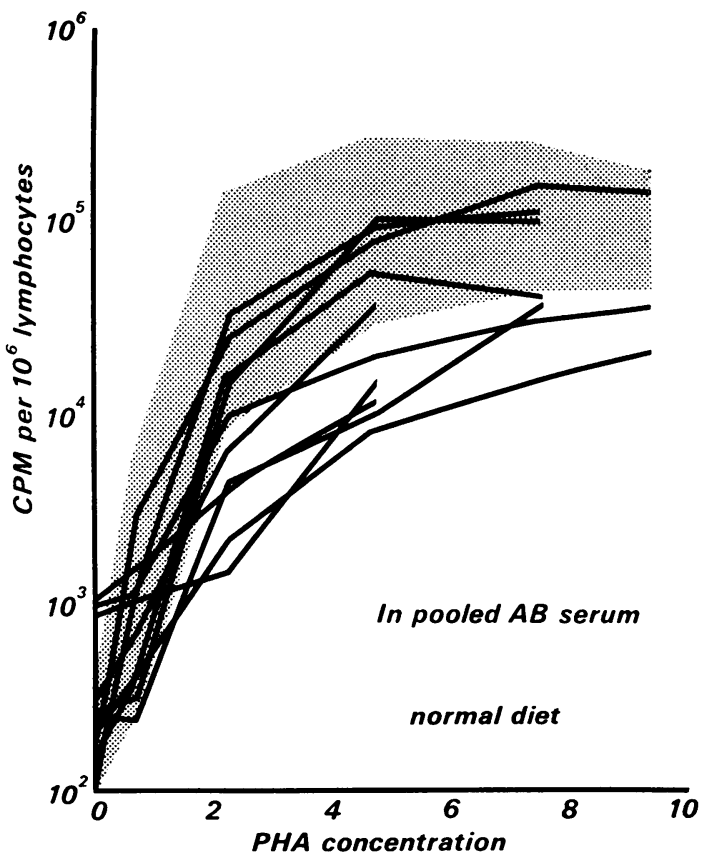

Fig. 1 Lymphocyte transformation in response to PHA in coeliac patients taking a normal diet compared with healthy controls. (Range of results in controls indicated by the shaded area). 

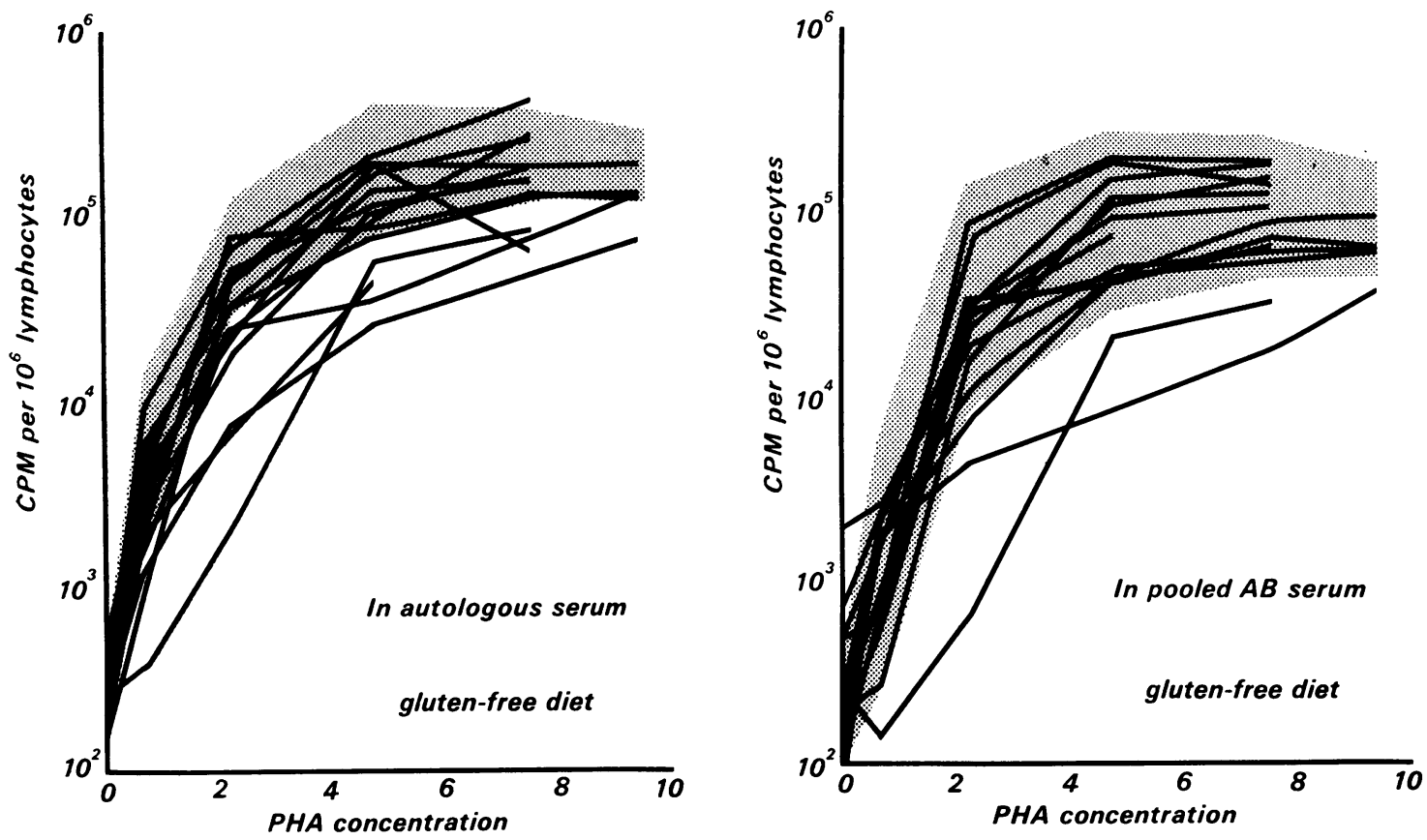

Fig. 2 Lymphocyte transformation in response to PHA in coeliac patients taking a GFD compared with healthy controls. (Range of results in controls indicated by the shaded area).

Lymphocytotoxic antibodies were detected in three patients and in two of these transformation was more depressed in autologous serum.

No correlation could be established between transformation and deficiency of any particular nutrient measured. Furthermore, some subjects with normal transformation had obvious deficiencies and some with subnormal transformation had normal nutritional measurements. There was no correlation between the response and the age of either patients or controls, and the age ranges of the patients and the controls were similar.

Although some patients were taking medications none of these included any of the substances which have been recognised as affecting lymphocyte transformation and some patients with low responses were taking no medication.

\section{MANTOUX TESTS}

The results are presented in Table 2 . Only $22 \%$ of the coeliac patients had positive tests compared with $85 \%$ of the controls. This difference is highly significant $(P<0.001$ using the chi squared test). One patient tested before and six months after starting a GFD remained negative. Two patients remained negative after BCG vaccination, one had responded well to a GFD, the other would not adhere to the diet. In all except three of the negative tests no induration was seen, and in these three the diameter of induration was 3-4 $\mathrm{mm}$.

\section{Discussion}

Using both in vitro and in vivo techniques, CMI has been shown to be depressed in most untreated coeliac patients. As assessed by PHA induced lymphocyte transformation CMI usually improves (often to normal) after treatment with a GFD. On the other hand, Mantoux tests were as commonly negative in the treated as untreated patients. This may reflect depressed CMI at the time of potential immunisation rather than at the time of testing. However, two patients who were tested before and after BCG vaccination remained negative, although one had responded well to the GFD. Meaningful conclusions cannot be drawn from these two reports and further studies of active immunisation in coeliac disease are indicated.

The depression of CMI could partly be explained by a depressing factor in the serum, although the factor has not been defined. Lymphocytotoxic antibodies could not be incriminated in the majority. One obvious possible cause of depressed CMI in coeliac disease is the nutritional deficiency conse- 


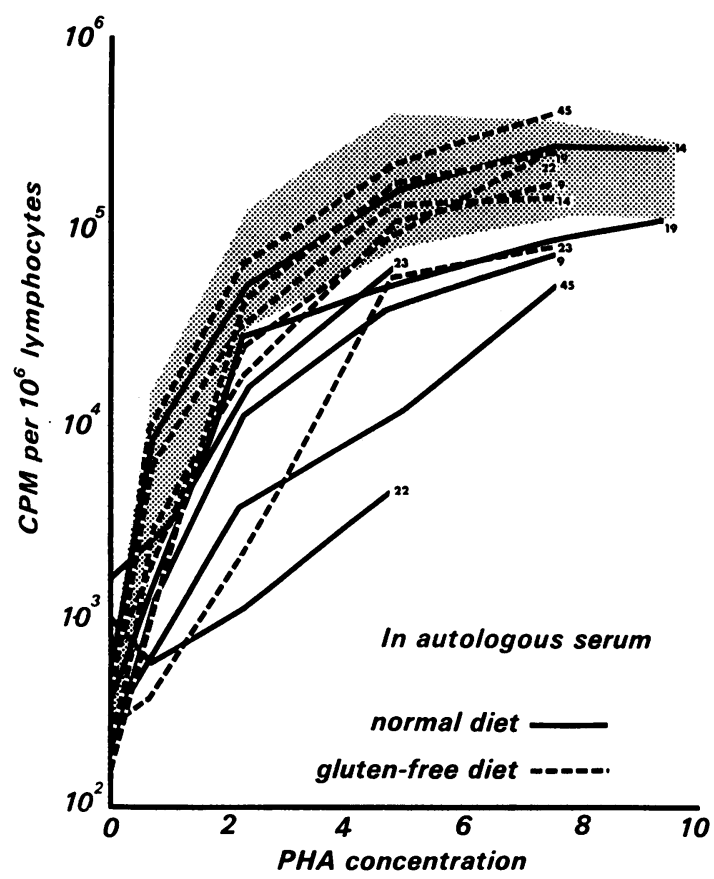

Fig. 3 Lymphocyte transformation in response to $P H A$ in six coeliac patients both before and after treatment with a GFD. (Range of results in controls indicated by the shaded area).

quent upon the malabsorption, as CMI is known to be depressed in severe malnutrition (Geefhuysen $\boldsymbol{e t}$ al., 1971; Smythe et al., 1971). However, in this study no correlation was found between general nutritional status or deficiency of individual nutrients and the results of lymphocyte transformation. Other possibilities are exhaustion atrophy of an overworked lymphoreticular system (McCarthy et al., 1966) or excessive lymphocyte loss from the damaged mucosa (Weetman et al., 1974), as in intestinal lymphangiectasia in which there is a profound depression of CMI and an increased risk of malignancy (Waldmann et al., 1972). Although T-cell counts were not performed in this study, reduction in peripheral blood T-cells is unlikely wholly to explain the findings, as the reported magnitude of reduction of T-cell numbers in untreated coeliac disease (O'Donoghue et al., 1975 ) is considerably less than the magnitude of depression of lymphocyte transformation observed in many of the patients of this study. However, this could be a contributory factor.

The clinical consequences of the depressed CMI in coeliac disease are not known. An excessive incidence of infections, common to many states of depressed immunity, is not a recognised feature of coeliac disease, although it is of interest that direct questioning of the 18 patients studied by lymphocyte transformation revealed that fungal infections had occurred in four-oral or vaginal candidiasis in three and abdominal actinomycosis in one. Probably of greater revelance is the high risk of malignancy in patients with coeliac disease, since patients with immunodeficiency from other causes are known to have an increased risk of malignancy possibly due to loss of immunosurveillance. If depressed immunity in coeliac disease is related to the development of malignancy, the case for a strict GFD in all patients is reinforced by the finding of improvement of CMI as assessed by lymphocyte transformation.

This work forms part of the London MD Thesis (1975) of B.B.S. We thank Professor G. Gowland, University of Leeds, for instruction in the techniques of lymphocyte transformation and for advice.

\section{References}

Ansaldi, N., DeSanctis, C., Fabris, C., and Ponzone, A. (1970). Blastizzazione linfocitaria in vitro con fitoemoagglutinina e con glutine inbanbini affetti da morbo celiaco. Minnesota Pediatrics, 22, 1907-1912.

Austad, W. I., Cornes, J. S., Gough, K. R., McCarthy, C. F., and Read, A. E. (1967). Steatorrhea and malignant lymphoma. American Journal of Digestive Diseases, 12, 475-490.

Baker, P. G., Jones, J. V., Peacock, D. B., and Read, A. E. (1974). Evidence of immunodeficiency in patients with coeliac disease (Abstract). Gut, 15, 835.

Beale, A. J., Parish, W. E., Douglas, A. P., and Hobbs, J. R. (1971). Impaired IgA responses in coeliac disease. Lancet, 1, 1198-1200.

Blecher, T. E., Brzechwa-Ajdukiewicz, A., McCarthy, C. F., and Read, A. E. (1969). Serum immunoglobulins and lymphocyte transformation studies in coeliac disease. Gut, $10,57-62$.

Booth, C. C. (1970). Enterocyte in coeliac disease. British Medical Journal, 3, 725-731; and 4, 14-17.

Burnet, F. M. (1967). Immunological aspects of malignant disease. Lancet, 1, 1171-1174.

Caspary, E. A., and Hughes, D. (1972). Liquid scintillation counting techniques in lymphocyte transformation in vitro measured by tritiated thymidine uptake. Journal of Immunological Methods, 1, 263-272.

Cooke, W. T. (1970). Malignancy and adult coeliac disease. In Coeliac Disease, pp. 198-202. Edited by C. C. Booth and R. H. Dowling. Churchill: Edinburgh.

Fitzgerald, M. G. (1971). The establishment of a normal human population dose-response curve for lymphocytes cultured with PHA (Phytohaemagglutinin). Clinical and Experimental Immunology, 8, 421-425.

Fitzgerald, M. G. (1972). A satisfactory quantitative test of lymphocyte response to phytohaemagglutinin for the definition of normal control values and recognition of immunological defects. Journal of Clinical Pathology, 25, 163-168.

Geefhuysen, J., Rosen, E. U., Katz, J., Ipp, T., and Metz, J. (1971). Impaired cellular immunity in kwashiorkor with improvement after therapy. British Medical Journal, 4, 527-529.

Gough, K. R., Read, A. E., and Naish, J. M. (1972). Intes- 
tinal reticulosis as a complication of idiopathic steatorrhoea. Gut, 3, 232-239.

Harris, O. D., Cooke, W. T., Thompson, H., and Waterhouse, J. A. H. (1967). Malignancy in adult coeliac disease and idiopathic steatorrhoea. American Journal of Medicine, 42, 899-912.

Housley, J., Asquith, P., and Cooke, W. T. (1969). Immune response to gluten in adult coeliac disease. British Medical Journal, 2, 159-161.

Hughes, D., and Caspary, E. A. (1970). Lymphocyte transformation in vitro measured by tritiated thymidine uptake. I. Lymphocyte culture techniques. International Archives of Allergy, 37, 506-531.

Lowenfels, A. B. (1973). Why are small-bowel tumours so rare? Lancet, 1, 24-26.

Maclaurin, B. P., Cooke, W. T., and Ling, N. R. (1971). Impaired lymphocyte reactivity against tumour cells in patients with coeliac disease. Gut, 12, 794-800.

McCarthy, C. F., Fraser, I. D., Evans, K. T., and Read, A. E. (1966). Lymphoreticular dysfunction in idiopathic steatorrhoea. Gut, 7, 140-148.

Morganroth, J., Watson, D. W., and French, A. B. (1972). Cellular and humoral sensitivity to gluten fractions in patients with treated nontropical sprue. American Journal of Digestive Diseases, 17, 205-212.

O'Donoghue, D. P., Lancaster-Smith, M., and Kumar, P. J. (1975). Depletion of thymus-dependent lymphocytes in adult coeliac disease (Abstract). Gut, 16, 392.

Paty, D. W., and Hughes, D. (1972). Lymphocyte transformation using whole blood cultures: an analysis of responses. Journal of Immunological Methods, 2, 99-114.

Popovíc, O., Andrejevic, M., Pendíc, B., Lovríc, L., and Djordjevíc, V. (1970). Lymphocyte transformation in coeliac disease (Letter). Lancet, 2, 725.

Richter, M., and Naspitz, C. K. (1967). The variation in response of human peripheral lymphocytes to phytohemagglutinin in vitro. International Archives of Allergy, 32, 288293.

Schellekens, P. T. A., and Eijsvoogel, V. P. (1968). Lymphocyte transformation in vitro. I. Tissue culture conditions and quantitative measurements. Clinical and Experimental Immunology, 3, 571-584.

Smythe, P. M., Schonland, M., Brereton-Stiles, G. G., Coovadia, H. M., Grace, H. J., Loening, W. E. K., Mafoyane, A., Parent, M. A., and Vos, G. H. (1971). Thymolymphatic deficiency and depression of cellmediated immunity in protein-calorie malnutrition. Lancet, 2,939-944.

Stokes, P. L., and Holmes, G. K. T. (1974). Malignancy. Clinics in Gastroenterology, 3, 159-170.

Terasaki, P. I., and McClelland, J. D. (1964). Microdroplet assay of human serum cytotoxins. Nature, 204, 998-1000.

Waldmann, T. A., Strober, W., and Blaese, R. M. (1972). Immunodeficiency disease and malignancy. Annals of Internal Medicine, 77, 605-628.

Wattenberg, L. W. (1966). Carcinogen-detoxifying mechanisms in the gastrointestinal tract. Gastroenterology, 51, 932-935.

Weetman, A. P., Haggith, J., and Douglas, A. P. (1974). Enteric loss of lymphocytes in coeliac disease and in Crohn's disease (Abstract). Gut, 15, 823.

Winter, G. C. B., McCarthy, C. F., Read, A. E., and Yoffey, J. M. (1967). Development of macrophages in phytohaemagglutinin cultures of blood from patients with idiopathic steatorrhoea and with cirrhosis. British Journal of Experimental Pathology, 48, 66-80. 